\title{
Prognostic Factors for Recovery from Sudden Sensorineural Hearing Loss: A Retrospective Study
}

\author{
Woo Seok Kang ${ }^{1 *}$, Chan Joo Yang ${ }^{1 *}$, Myungjoo Shim², Chan II Song ${ }^{3}$, Tae Su Kim \\ Hyun Woo Lim ${ }^{5}$, Joong Ho Ahn ${ }^{1}$, Hong Ju Park', and Jong Woo Chung ${ }^{1}$ \\ ${ }^{1}$ Department of Otorhinolaryngology-Head \& Neck Surgery, Asan Medical Center, University of Ulsan College of Medicine, Seoul, \\ ${ }^{2}$ Department of Otorhinolaryngology, Hallym Hospital, Incheon, \\ ${ }^{3}$ Department of Otolaryngology-Head and Neck Surgery, Jeju National University School of Medicine, Jeju, \\ ${ }^{4}$ Department of Otolaryngology, Kangwon National University School of Medicine, Chuncheon, \\ ${ }^{5}$ Department of Otolaryngology, Gangneung Asan Hospital, University of Ulsan College of Medicine, Gangneung, Korea
}

\begin{abstract}
Background and Objectives: This study aimed to investigate prognostic factors in patients with idiopathic sudden sensorineural hearing loss (ISSNHL). Subjects and Methods: From January 2007 to December 2011, a retrospective chart review identified 494 consecutive patients with ISSNHL. Demographic, audiometric, and clinical data were analyzed using a logistic regression test. Results: Hearing recovery from ISSNHL was significantly associated with factors such as age, duration from onset of symptoms to commencement of treatment, severity of the initial pure tone threshold, and the treatment method. Intratympanic (IT) steroid administration alone showed a comparable efficiency to oral steroid administration with or without IT steroid injection. In patients who received IT steroid injection, the duration from onset to treatment, severity of initial hearing loss, and sequential IT steroid injection following systemic steroid administration were statistically associated with hearing improvement. Conclusions: Age, severity of initial pure tone threshold, duration from onset to treatment, initial speech discrimination, and initial pure tone threshold are statistically significant prognostic factors related to hearing improvement in ISSNHL. IT steroid injection as an initial single treatment is comparable to systemic oral steroid administration.
\end{abstract}

J Audiol Otol 2017;21(1):9-15

KEY WORDS: Corticosteroid · Hearing · Idiopathic sudden sensorineural hearing loss . Prognosis

\section{Introduction}

Idiopathic sudden sensorineural hearing loss (ISSNHL) is defined as sudden-onset hearing loss without a definite cause. Because recovery from ISSNHL is possible within 23 months after its onset [1], early treatment with systemic steroids [2], intratympanic (IT) steroid injection [3], and/or hyperbaric oxygen therapy is necessary. However, a serviceable degree of hearing is not recovered in one-third to two-third of patients, even after these patients receive treatments that have

This is an Open Access article distributed under the terms of the Creative Commons Attribution Non-Commercial License (http://creativecommons.org/licenses/by-nc/4.0/) which permits unrestricted non-commercial use, distribution, and reproduction in any medium, provided the original work is properly cited. been deemed appropriate by evidence-based analysis $[2,4-6]$.

Although the etiology of ISSNHL is not well clarified, inflammation or microvascular compromise of the labyrinth or cochlea nerve has been suggested [7]. Given the ambiguity of the target of the treatment, standard treatments may not be adequate for recovery of the end organs in some patients. Therefore, systemic or IT steroid treatment is effective only in patients with a good prognosis.

Many prognostic factors have been reported for ISSNHL. More severe initial hearing loss, advanced age, vertigo, descending type of audiogram, cardiovascular risk factors such as diabetes, hypercholesterolemia, and hyperglycemia were shown to be negatively correlated with recovery [7]. Recently, metabolic factors such as diabetes, hyperlipidemia, and 
hyperglycemia have been shown to be significantly related to recovery from hearing loss [8-10].

Systemic steroids are the standard initial treatment for ISSNHL, although a placebo-controlled study showed that systemic steroids did not result in superior improvement [11]. IT steroid injections are effective when they are used alone or with systemic steroid administration. Although improvement appears to be superior when a combination of systemic and IT steroids is used, a consensus does not exist regarding the use of the combination method $[3,12,13]$.

In this study, we aimed to find objective prognostic factors other than those previously reported and to determine the best combination of systemic administration and IT steroid injection.

\section{Subjects and Methods}

A retrospective chart review was performed between January 2007 and December 2011, and 494 consecutive patients with ISSNHL were enrolled in the present study. The Institutional Review Board of Asan Medical Center approved the study protocol (2012-0799).

Oral prednisolone was used as the initial treatment. Methylprednisolone $(0.8 \mathrm{mg} / \mathrm{kg})$ was given orally once a day for the first 9 days, and this dose was tapered over the next 5 days. IT dexamethasone $(5 \mathrm{mg} / \mathrm{mL})$ was administered under several different conditions: together with systemic steroid treatment, following systemic steroid treatment, or alone in some cases. Dexamethasone was injected so that it filled more than half of the tympanic cavity; during treatment, the patient was positioned with his/her head turned to the opposite side. After the injection, the patient was instructed to maintain the position and to avoid swallowing for 30 minutes.

Pure tone averages (PTA) were calculated by averaging the pure tone levels at 500, 1,000, 2,000, and 4,000 Hz. Two months after the initial treatment, follow-up pure tone audiometry was performed. The hearing outcome was assessed based on Siegel's criteria: 1) complete recovery of final hearing, defined as better than $25 \mathrm{~dB}$ regardless of initial hearing, 2) partial recovery, defined as $\geq 15 \mathrm{~dB}$ of gain and a final hearing level between 25 and $45 \mathrm{~dB}, 3$ ) slight improvement, defined as $\geq 15 \mathrm{~dB}$ of gain and final hearing worse than 45 $\mathrm{dB}$, and 4) no improvement, defined as $<15 \mathrm{~dB}$ of gain or final hearing worse than $75 \mathrm{~dB}$ [14].

Data were obtained through medical chart review in order to validate the expected prognostic factors such as duration from the onset of symptoms to commencement of treatment, initial pure tone threshold, speech discrimination, pattern of hearing loss, medical history, blood test results, and treat- ment options.

We used SPSS 18.0 (SPSS software; SPSS Inc., Chicago, IL, USA) for statistical analysis. A logistic regression test was used to assess the prognostic value of the clinical factors, comorbidities, laboratory findings, and treatment options. Variables with $p<0.01$ in univariate analyses were selected for multivariate analysis by using a logistic regression test to evaluate the independent prognostic value of each factor. For each test, a $p$ value $\leq 0.05$ was considered statistically significant.

\section{Results}

Among 494 participants, 265 were men and 229 were women. The initial average hearing threshold was $72 \mathrm{~dB}$ and the final hearing level was $48 \mathrm{~dB}$.

In univariate analysis, hearing recovery was significantly related to factors such as age, vertigo, initial pure tone threshold, initial speech discrimination score, duration from onset to treatment, pattern of hearing loss, comorbidities of diabetes and hyperlipidemia, treatment method, duration from onset to IT steroid injection, and interval of IT steroid injection (Table 1-3).

Steroid alone was administered orally in 235 patients (47\%), IT dexamethasone was co-administered with oral steroid in 128 patients, and IT dexamethasone was given following oral steroid administration in 103 patients. IT dexamethasone was used alone in 28 patients because of medical conditions such as concomitant diabetes. After treatment, hearing completely improved in $26 \%$ of patients, partially or slightly improved in $40 \%$ of patients, and did not improve in $34 \%$ of patients (Table 3). Oral steroid administration with or without IT steroid injection completely or partially improved hearing in 218 patients out of 466 (46.8\%). IT steroid administration alone demonstrated a similar efficiency to oral steroid administration with or without IT steroid injection (42.8\%).

By using the factors that were significant in univariate analysis, multivariate analysis showed that age, duration from onset of symptoms to commencement of treatment, initial speech discrimination, severity of the initial pure tone threshold, and the treatment method were statistically related to the patients' prognoses (Table 4). Simultaneous and sequential IT dexamethasone injection showed a worse prognosis for hearing improvement (odds ratio $=1.523, p=0.046$; odds ratio $=3.457, p<0.001$, respectively) compared to treatment with oral steroid alone in multivariate analysis (Table 4).

Analysis of the hearing results of patients who received IT steroid injection revealed that the duration from onset to treatment, severity of initial hearing loss, and IT steroid injection following systemic steroid administration were statis- 
Table 1. Demographic and clinical factors related to recovery of hearing

\begin{tabular}{|c|c|c|c|c|c|c|}
\hline Variable & $\begin{array}{c}\text { Complete } \\
\text { recovery, } \\
\text { n (\%) }\end{array}$ & $\begin{array}{l}\text { Partial } \\
\text { recovery, } \\
\text { n (\%) }\end{array}$ & $\begin{array}{c}\text { Slight } \\
\text { improvement, } \\
n(\%)\end{array}$ & $\begin{array}{c}\text { No } \\
\text { improvement, } \\
\mathrm{n}(\%)\end{array}$ & $\begin{array}{c}\text { OR } \\
\text { (recovery } \rightarrow \text { no } \\
\text { improvement) }\end{array}$ & $p^{*}$ \\
\hline \multicolumn{7}{|l|}{ Gender } \\
\hline Male & $67(25.3)$ & $60(22.7)$ & $49(75.4)$ & $89(33.6)$ & 1 & \\
\hline Female & $62(27.1)$ & $41(17.9)$ & $46(20.1)$ & $80(34.9)$ & 1.035 & 0.833 \\
\hline Age & & & & & & 0.001 \\
\hline Mean (years) & 44.6 & 53.9 & 53.5 & 51.8 & 1.017 & \\
\hline \multicolumn{7}{|l|}{ Associated symptom } \\
\hline \multicolumn{7}{|l|}{ Vertigo } \\
\hline No & $113(32.1)$ & $79(22.4)$ & $45(12.8)$ & $115(32.7)$ & 1 & \\
\hline Yes & $16(11.3)$ & $22(15.5)$ & $50(35.2)$ & $54(38.0)$ & 2.086 & $<0.001$ \\
\hline \multicolumn{7}{|l|}{ Tinnitus } \\
\hline No & $32(24.1)$ & $35(26.3)$ & $22(16.5)$ & $44(33.1)$ & 1 & \\
\hline Yes & $97(27.0)$ & $66(18.4)$ & $73(20.3)$ & $123(34.3)$ & 1.052 & 0.779 \\
\hline Initial PTA threshold & & & & & & $<0.001$ \\
\hline Mild & $31(46.3)$ & $27(40.3)$ & $0(0)$ & $9(13.4)$ & 1 & \\
\hline Moderate & $62(33.0)$ & $36(19.1)$ & $5(2.7)$ & $85(45.2)$ & 3.467 & \\
\hline Severe & $27(25.5)$ & $27(25.5)$ & $17(16.0)$ & $35(33.0)$ & 3.191 & \\
\hline Profound & $8(6.1)$ & $11(8.3)$ & $73(55.3)$ & $40(30.3)$ & 6.018 & \\
\hline Initial SD & & & & & 0.990 & $<0.001$ \\
\hline Mean (\%) & 57.4 & 55.8 & 5.9 & 40.5 & & \\
\hline Duration from onset to treatment & & & & & & $<0.001$ \\
\hline Mean (days) & 4.74 & 6.82 & 3.75 & 10.5 & & \\
\hline Pattern of hearing loss & & & & & & 0.007 \\
\hline Upward sloping & $50(56.8)$ & $16(18.2)$ & $10(11.4)$ & $12(13.6)$ & 1 & \\
\hline Downward sloping & $16(12.0)$ & $35(26.3)$ & $16(12.0)$ & $66(49.6)$ & 7.590 & \\
\hline Tent & $12(32.4)$ & $15(40.5)$ & $1(2.7)$ & $9(24.3)$ & 2.085 & \\
\hline Flat & $25(26.3)$ & $28(29.5)$ & $10(10.5)$ & $32(33.7)$ & 3.451 & \\
\hline Notching & $21(51.2)$ & $4(9.8)$ & $3(7.3)$ & $13(31.7)$ & 8.890 & \\
\hline No response & $5(5.0)$ & $3(3.0)$ & $55(55.0)$ & $37(37.0)$ & 1.781 & \\
\hline
\end{tabular}

*assessed by using the logistic regression test (univariate analysis). PTA: pure tone audiometry, OR: odds ratio, SD: speech discrimination

tically significant prognostic factors for recovery from hearing loss (Table 5).

\section{Discussion}

The possible etiologies of ISSNHL are vascular compromise and/or inflammation in the labyrinth or cochlear nerve [7]. Vascular compromise results in increased reactive oxygen species and possible damage to the hair cells [15]. Ischemia induces morphological changes in the outer and inner hair cells and the organ of Corti, and the duration of ischemia correlates with the severity of the morphological changes $[16,17]$. Recovery from hearing loss following ischemic events may be expected unless tissue damage is irreversible. The inflammatory process of the inner ear or cochlear nerve may induce structural and metabolic changes. Irreversible changes may occur when the sensory cells or axonal cells are destroyed.

The degree of hearing loss is related to the amount of deranged hair cells and damaged neural cells. Several reports described a relationship between the number of remaining hair cells and the residual hearing level in noise-induced hearing loss or other sensorineural hearing loss [18,19]. Recovery of damaged cells can be expected in the absence of further pathologic processes and when sufficient amounts of cell protective agents such as D-JNKI-1 peptide, brain-derived neurotrophic factor, and anti-oxidants are present [20].

The resistance of the inner ear sensory hair cells and cochlear nerve against the pathologic process described above is reported to depend on aging [21]. This implies that the inner ear hair cells have better resistance to oxidative stress in younger animals. In the present study, recovery of hearing 
Prognostic Factors for ISSNHL

Table 2. Comorbidities and laboratory abnormalities related to recovery of hearing

\begin{tabular}{|c|c|c|c|c|c|c|}
\hline Variable & $\begin{array}{c}\text { Complete } \\
\text { recovery, } \\
\mathrm{n}(\%)\end{array}$ & $\begin{array}{l}\text { Partial } \\
\text { recovery, } \\
\text { n (\%) }\end{array}$ & $\begin{array}{c}\text { Slight } \\
\text { improvement, } \\
\mathrm{n}(\%)\end{array}$ & $\begin{array}{c}\text { No } \\
\text { improvement, } \\
\mathrm{n}(\%)\end{array}$ & $\begin{array}{c}\text { OR } \\
\text { (recovery } \rightarrow \text { no } \\
\text { improvement) }\end{array}$ & $p^{*}$ \\
\hline \multicolumn{7}{|l|}{ Hypertension } \\
\hline No & $97(31.1)$ & $55(17.6)$ & $57(18.3)$ & $103(33.0)$ & 1 & \\
\hline Yes & $31(18.2)$ & $41(24.1)$ & $38(22.4)$ & $60(35.3)$ & 1.361 & 0.070 \\
\hline \multicolumn{7}{|l|}{ Diabetes } \\
\hline No & $116(29.4)$ & 77 (19.5) & $72(18.3)$ & $129(32.7)$ & 1 & \\
\hline Yes & $12(13.6)$ & $19(21.6)$ & $23(26.1)$ & $34(38.1)$ & 1.636 & 0.018 \\
\hline \multicolumn{7}{|l|}{ Dyslipidemia } \\
\hline No & $114(27.7)$ & $86(20.9)$ & 77 (18.7) & $134(32.6)$ & 1 & \\
\hline Yes & $14(20.0)$ & $9(12.9)$ & $18(25.7)$ & $29(41.4)$ & 1.604 & 0.044 \\
\hline \multicolumn{7}{|l|}{ Stroke } \\
\hline No & $127(26.9)$ & $96(20.3)$ & $90(19.1)$ & $159(33.7)$ & 1 & \\
\hline Yes & $0(0)$ & $0(0)$ & $4(57.1)$ & $3(42.9)$ & 2.662 & 0.128 \\
\hline \multicolumn{7}{|l|}{$\mathrm{Ml}$} \\
\hline No & $123(26.9)$ & $94(20.6)$ & $89(19.5)$ & $151(33.0)$ & 1 & \\
\hline Yes & $4(18.2)$ & $2(9.1)$ & $5(22.7)$ & $11(50.0)$ & 2.053 & 0.079 \\
\hline \multicolumn{7}{|l|}{ Sleep disturbance } \\
\hline No & $126(26.8)$ & $95(20.2)$ & $90(19.1)$ & 159 (33.8) & 1 & \\
\hline Yes & $1(12.5)$ & $1(12.5)$ & $3(37.5)$ & $3(37.5)$ & 1.664 & 0.408 \\
\hline \multicolumn{7}{|l|}{ Smoking } \\
\hline No & $85(27.5)$ & $59(19.1)$ & $58(18.8)$ & $107(34.6)$ & 1 & \\
\hline Quit & $8(21.6)$ & $5(13.5)$ & $15(40.5)$ & $9(24.3)$ & 1.075 & \\
\hline Current & $16(28.6)$ & $10(17.9)$ & $8(14.3)$ & $22(39.3)$ & 1.045 & \\
\hline Alcohol consumption & & & & & & 0.651 \\
\hline No & $73(25.9)$ & $52(18.4)$ & $57(20.2)$ & $100(35.5)$ & 1 & \\
\hline Social & $34(32.4)$ & $19(18.1)$ & $19(18.1)$ & $33(31.4)$ & 0.780 & \\
\hline Heavy & $2(13.3)$ & $3(20.0)$ & 5 (33.3) & 5 (33.3) & 1.281 & \\
\hline \multicolumn{7}{|l|}{ Platelet abnormality } \\
\hline No & $116(27.4)$ & $84(19.9)$ & $81(19.1)$ & $142(33.6)$ & 1 & \\
\hline Yes & $10(16.9)$ & $15(25.4)$ & $12(20.3)$ & $22(37.3)$ & 2.023 & 0.157 \\
\hline \multicolumn{7}{|c|}{ Coagulation abnormality } \\
\hline No & $97(26.1)$ & $72(19.4)$ & $70(18.9)$ & $132(35.6)$ & 1 & \\
\hline Yes & $22(25.9)$ & $21(24.7)$ & $18(21.2)$ & $24(28.2)$ & 0.834 & 0.525 \\
\hline BMl & & & & & & 0.888 \\
\hline Low weight & $3(27.3)$ & $3(27.3)$ & $2(18.2)$ & $3(27.3)$ & 0.800 & \\
\hline Normal & $41(27.5)$ & $24(16.1)$ & $35(23.5)$ & $49(32.9)$ & 1 & \\
\hline Obese & $45(26.8)$ & $33(19.6)$ & $31(18.5)$ & $59(35.1)$ & 1.015 & \\
\hline \multicolumn{7}{|l|}{ Lipid profile } \\
\hline \multicolumn{7}{|c|}{ Hypercholesterolemia } \\
\hline No & $84(26.6)$ & $69(21.8)$ & $51(16.1)$ & $112(35.4)$ & 1 & \\
\hline Yes & $40(24.5)$ & $30(18.4)$ & $41(25.2)$ & $52(31.9)$ & 1.040 & 0.818 \\
\hline \multicolumn{7}{|l|}{ TG $\geq 130$} \\
\hline No & $31(24.6)$ & $35(27.8)$ & $21(16.7)$ & $39(31.0)$ & 1 & \\
\hline Yes & $1(10.0)$ & $5(50.0)$ & $2(20.0)$ & $2(20.0)$ & 1.168 & 0.771 \\
\hline \multicolumn{7}{|l|}{$\mathrm{LDL} \geq 200$} \\
\hline No & $31(26.3)$ & $33(28.0)$ & $20(16.9)$ & $34(31.0)$ & 1 & \\
\hline Yes & $0(0)$ & $2(25.0)$ & $2(25.0)$ & $4(50.0)$ & 3.115 & 0.086 \\
\hline
\end{tabular}


Table 2. Comorbidities and laboratory abnormalities related to recovery of hearing (Continued)

\begin{tabular}{|c|c|c|c|c|c|c|}
\hline Variable & $\begin{array}{c}\text { Complete } \\
\text { recovery, } \\
\text { n (\%) }\end{array}$ & $\begin{array}{l}\text { Partial } \\
\text { recovery, } \\
\text { n (\%) }\end{array}$ & $\begin{array}{c}\text { Slight } \\
\text { improvement, } \\
\mathrm{n}(\%)\end{array}$ & $\begin{array}{c}\text { No } \\
\text { improvement, } \\
n(\%)\end{array}$ & $\begin{array}{c}\text { OR } \\
\text { (recovery } \rightarrow \text { no } \\
\text { improvement) }\end{array}$ & $p^{*}$ \\
\hline \multicolumn{7}{|l|}{$\mathrm{HDL}<60$} \\
\hline No & $7(20.6)$ & $12(35.3)$ & $4(11.8)$ & $11(32.4)$ & 1 & \\
\hline Yes & $25(25.3)$ & 27 (27.3) & $17(17.2)$ & $30(30.3)$ & 1.287 & 0.732 \\
\hline \multicolumn{7}{|l|}{ TFT abnormalities } \\
\hline No & $24(35.8)$ & $16(23.9)$ & $12(17.9)$ & $15(22.4)$ & 1 & \\
\hline Yes & $5(21.7)$ & $5(21.7)$ & $7(30.4)$ & $6(26.1)$ & 1.686 & 0.223 \\
\hline \multicolumn{7}{|l|}{ Zinc abnormality } \\
\hline No & $19(35.8)$ & $15(28.3)$ & $8(15.1)$ & $11(20.8)$ & 1 & \\
\hline Yes & $3(21.4)$ & $4(28.6)$ & $3(21.4)$ & $4(28.6)$ & 0.797 & 0.680 \\
\hline
\end{tabular}

Table 3. Treatment options in relation to recovery of hearing

\begin{tabular}{|c|c|c|c|c|c|c|}
\hline Variable & $\begin{array}{c}\text { Complete } \\
\text { recovery, } \\
\text { n (\%) }\end{array}$ & $\begin{array}{l}\text { Partial } \\
\text { recovery, } \\
\text { n (\%) }\end{array}$ & $\begin{array}{c}\text { Slightly } \\
\text { improvement, } \\
\mathrm{n}(\%)\end{array}$ & $\begin{array}{c}\text { No } \\
\text { improvement, } \\
n(\%)\end{array}$ & $\begin{array}{c}\text { OR } \\
\text { (recovery } \rightarrow \text { no } \\
\text { improvement) }\end{array}$ & $p^{*}$ \\
\hline Treatment & $129(26.1)$ & $101(20.4)$ & $95(19.2)$ & $169(34.2)$ & & \\
\hline Oral steroid only & $80(34.0)$ & $63(26.8)$ & $37(15.7)$ & $55(23.4)$ & 1 & $<0.001$ \\
\hline Concurrent & $41(32.0)$ & $15(11.7)$ & $21(16.4)$ & $51(39.8)$ & 1.741 & 0.007 \\
\hline Sequential & $6(5.8)$ & $13(12.6)$ & $32(31.1)$ & $52(50.5)$ & 4.202 & $<0.001$ \\
\hline IT steroid only & $2(7.1)$ & $10(35.7)$ & $5(17.9)$ & $11(39.3)$ & 2.441 & 0.011 \\
\hline \multicolumn{7}{|l|}{ Admission } \\
\hline No & $73(28.7)$ & $43(16.9)$ & $52(20.5)$ & $86(33.9)$ & 1 & \\
\hline Yes & $56(23.3)$ & $58(23.2)$ & $43(17.9)$ & $83(34.6)$ & 1.073 & 0.663 \\
\hline \multicolumn{7}{|c|}{ Duration from onset to IT steroid } \\
\hline Mean (days) & 8.7 & 21.3 & 18.4 & 23.6 & 1.021 & 0.001 \\
\hline \multicolumn{7}{|l|}{ IT steroid interval } \\
\hline 1 day (everyday) & $39(29.5)$ & $18(13.6)$ & $24(18.2)$ & $51(38.6)$ & 1 & \\
\hline$>1$ day & $90(24.9)$ & $83(22.9)$ & $71(19.6)$ & $118(32.6)$ & 2.001 & 0.003 \\
\hline \multicolumn{7}{|l|}{ Number of IT steroids } \\
\hline$\leq 3$ & $14(15.7)$ & $18(20.2)$ & $20(22.5)$ & $37(41.6)$ & 1 & \\
\hline$>3$ & $36(21.4)$ & $18(10.7)$ & $38(22.6)$ & $76(45.2)$ & 0.865 & 0.756 \\
\hline
\end{tabular}

Systemic steroid administration followed by IT steroid injection was defined as "sequential" treatment. *assessed by using the logistic regression test (univariate analysis). IT: intratympanic, OR: odds ratio

was lower in older patients with ISSNHL.

The following factors were found to be significantly related to hearing recovery in ISSNHL in this study: old age, worse initial hearing, worse initial speech discrimination score, longer duration from onset to treatment, descending type of initial audiogram, and the presence of diabetes or hyperlipidemia. Poor speech discrimination in elderly patients is related to the loss of cochlear neurons and is a characteristic feature of neural presbycusis [22]. Delayed maximal restoration of speech discrimination scores in ISSNHL patients may result from central modulation following altered activity of the auditory pathway caused by ISSNHL [23]. In our study, worse initial speech discrimination score was related to worse prog- nosis in patients with ISSNHL, while other study reported that patients with poorer initial speech discrimination scores were more likely to improve [24]. Although it is not known whether neural damage is worse than hair-cell damage in relation to recovery, patients with neural loss may have a worse prognosis.

IT steroid injection has attracted a lot of attention as a treatment option for ISSNHL. IT dexamethasone injection is an effective salvage treatment in patients with unsatisfactory recovery after initial systemic steroid treatment [25]. Simultaneous or sequential injections are reported to be more effective than systemic steroid alone $[12,13,26]$. However, we found that IT dexamethasone injection was a poor prognostic 
Table 4. Multivariate analysis for factors affecting recovery from sudden hearing loss $(n=490)$

\begin{tabular}{|c|c|c|c|c|}
\hline \multirow{2}{*}{ Variables } & \multirow{2}{*}{ OR } & \multicolumn{2}{|c|}{$95 \% \mathrm{Cl}$ for $\mathrm{OR}$} & \multirow{2}{*}{$p^{*}$} \\
\hline & & Lower & Upper & \\
\hline Age & 1.018 & 1.007 & 1.029 & 0.001 \\
\hline Duration from onset to treatment & 1.079 & 1.052 & 1.107 & $<0.001$ \\
\hline Initial speech discrimination & 1.017 & 1.005 & 1.028 & 0.00 \\
\hline \multicolumn{5}{|l|}{ Initial PTA threshold } \\
\hline Mild & 1 & & & $<0.001$ \\
\hline Moderate & 3.505 & 2.025 & 6.069 & $<0.001$ \\
\hline Severe & 3.37 & 1.850 & 6.139 & $<0.001$ \\
\hline Profound & 7.305 & 4.035 & 13.226 & $<0.001$ \\
\hline \multicolumn{5}{|l|}{ Treatment } \\
\hline Oral steroid only & 1 & & & $<0.001$ \\
\hline Concurrent & 1.523 & 1.022 & 2.271 & 0.046 \\
\hline Sequential & 3.457 & 2.178 & 5.488 & $<0.001$ \\
\hline IT steroid only & 1.560 & 0.714 & 3.408 & 0.232 \\
\hline
\end{tabular}

Systemic steroid administration followed by IT steroid injection is defined as "sequential" treatment. *assessed by using the logistic regression test. Cl: confidence interval, OR: odds ratio, PTA: pure tone audiometry, IT: intratympanic

Table 5. Multivariate analysis for factors affecting recovery of sudden hearing loss in patients treated with IT steroid injection ( $n=$ 259)

\begin{tabular}{|c|c|c|c|c|}
\hline \multirow{2}{*}{ Variables } & \multirow{2}{*}{ OR } & \multicolumn{2}{|c|}{$95 \% \mathrm{Cl}$ for $\mathrm{OR}$} & \multirow{2}{*}{$p^{*}$} \\
\hline & & Lower & Upper & \\
\hline Duration from onset to treatment & 1.06 & 1.028 & 1.093 & $<0.001$ \\
\hline \multicolumn{5}{|c|}{ Initial PTA threshold } \\
\hline Mild & 1 & & & \\
\hline Moderate & 3.499 & 1.557 & 7.864 & 0.003 \\
\hline Severe & 3.314 & 1.411 & 7.785 & 0.007 \\
\hline Profound & 4.741 & 2.045 & 10.99 & $<0.001$ \\
\hline \multicolumn{5}{|l|}{ Treatment } \\
\hline Concurrent & 1 & & & \\
\hline Sequential & 2.340 & 1.407 & 3.892 & $<0.001$ \\
\hline IT steroid only & 1.264 & 0.573 & 2.786 & 0.544 \\
\hline
\end{tabular}

Systemic steroid administration followed by IT steroid injection is defined as "sequential" treatment. *assessed by using the logistic regression test. Cl: confidence interval, OR: odds ratio, PTA: pure tone audiometry, IT: intratympanic

factor even after eliminating other confounding factors (Table 3). Patients whose hearing did not improve following systemic steroid administration usually sought secondary treatment, and sequential IT steroid injection was an option for those patients. Therefore, sequential IT steroid injection was found to be a poor prognostic factor.

IT dexamethasone injection was the only treatment used in 28 patients, and hearing was completely or partially improved in $42.8 \%$ of these patients. This result is similar to that observed for systemic steroid with or without IT dexamethasone injection $(46.8 \%)$. As already noted, IT dexameth- asone injection, as an initial treatment, is effective as systemic steroid therapy in patients with ISSNHL [27].

Various frequencies and intervals of IT dexamethasone injection are utilized for treatment. Chou, et al. [28] reported that daily injection is better than twice per week. However, in the present study, we found no statistically significant difference between injection intervals (once per week vs. more than twice per week). This result is consistent with a previous study showing that the interval of IT steroid injection does not correlate with hearing outcome [29]. The flow rate of perilymph and endolymph is extremely slow in guinea pigs [30,31], and the elimination half-time of dexamethasone from the scala tympani is shorter than that from the scala vestibuli in guinea pigs (22.5 $\mathrm{min}$ vs. $111 \mathrm{~min}$ ) [32]. Therefore, an administration frequency of twice or three times per week would probably result in a sufficient intralabyrinthine concentration of dexamethasone. However, the rate of inner ear fluid flow and the elimination half-time of dexamethasone from the inner ear are unknown in humans. Therefore, further studies are needed regarding the best frequency and interval of IT injection.

In conclusion, age, severity of initial hearing loss, duration from onset to treatment, initial speech discrimination score and initial pure tone threshold are statistically significant prognostic factors associated with hearing improvement in ISSNHL. IT steroid injection as an initial single treatment is comparable to systemic oral steroid administration in patients with medical conditions. Further studies are needed to determine the best IT steroid injection protocol, including the frequency and interval.

\section{Conflicts of interest}

The authors have no financial conflicts of interest.

\section{REFERENCES}

1) Kang WS, Kim YH, Park KH, Seo MH, Son EJ, Yoo SY, et al. Treatment strategy for sudden sensorineural hearing loss. Korean J Otorhinolaryngol-Head Neck Surg 2011;54:675-82.

2) Wilson WR, Byl FM, Laird N. The efficacy of steroids in the treatment of idiopathic sudden hearing loss. A double-blind clinical study. Arch Otolaryngol 1980;106:772-6.

3) Ahn JH, Yoo MH, Yoon TH, Chung JW. Can intratympanic dexamethasone added to systemic steroids improve hearing outcome in patients with sudden deafness? Laryngoscope 2008;118:279-82.

4) Byl FM Jr. Sudden hearing loss: eight years' experience and suggested prognostic table. Laryngoscope 1984;94:647-61.

5) Mattox DE, Simmons FB. Natural history of sudden sensorineural hearing loss. Ann Otol Rhinol Laryngol 1977;86:463-80.

6) Nosrati-Zarenoe R, Arlinger S, Hultcrantz E. Idiopathic sudden sensorineural hearing loss: results drawn from the Swedish national database. Acta Otolaryngol 2007;127:1168-75.

7) Kuhn M, Heman-Ackah SE, Shaikh JA, Roehm PC. Sudden sensorineural hearing loss: a review of diagnosis, treatment, and prognosis. Trends Amplif 2011;15:91-105. 
8) Lin CF, Lee KJ, Yu SS, Lin YS. Effect of comorbid diabetes and hypercholesterolemia on the prognosis of idiopathic sudden sensorineural hearing loss. Laryngoscope 2016;126:142-9.

9) Quaranta N, Squeo V, Sangineto M, Graziano G, Sabbà C. High total cholesterol in peripheral blood correlates with poorer hearing recovery in idiopathic sudden sensorineural hearing loss. PLoS One 2015;10:e 0133300.

10) Ryu OH, Choi MG, Park CH, Kim DK, Lee JS, Lee JH. Hyperglycemia as a potential prognostic factor of idiopathic sudden sensorineural hearing loss. Otolaryngol Head Neck Surg 2014;150:853-8.

11) Hultcrantz E, Nosrati-Zarenoe R. Corticosteroid treatment of idiopathic sudden sensorineural hearing loss: analysis of an RCT and material drawn from the Swedish national database. Eur Arch Otorhinolaryngol 2015;272:3169-75.

12) Kim SH, Jung SY, Kim MG, Byun JY, Park MS, Yeo SG. Comparison of steroid administration methods in patients with idiopathic sudden sensorineural hearing loss: a retrospective observational study. Clin Otolaryngol 2015;40:183-90.

13) Battaglia A, Lualhati A, Lin H, Burchette R, Cueva R. A prospective, multi-centered study of the treatment of idiopathic sudden sensorineural hearing loss with combination therapy versus highdose prednisone alone: a 139 patient follow-up. Otol Neurotol 2014; 35:1091-8.

14) Siegel LG. The treatment of idiopathic sudden sensorineural hearing loss. Otolaryngol Clin North Am 1975;8:467-73.

15) Nuttall AL. Sound-induced cochlear ischemia/hypoxia as a mechanism of hearing loss. Noise Health 1999;2:17-32.

16) Tabuchi K, Nishimura B, Tanaka S, Hayashi K, Hirose Y, Hara A. Ischemia-reperfusion injury of the cochlea: pharmacological strategies for cochlear protection and implications of glutamate and reactive oxygen species. Curr Neuropharmacol 2010;8:128-34.

17) Tabuchi K, Tsuji S, Fujihira K, Oikawa K, Hara A, Kusakari J. Outer hair cells functionally and structurally deteriorate during reperfusion. Hear Res 2002;173:153-63.

18) Liberman MC, Beil DG. Hair cell condition and auditory nerve response in normal and noise-damaged cochleas. Acta Otolaryngol 1979;88:161-76.

19) Patuzzi RB, Yates GK, Johnstone BM. Outer hair cell receptor current and sensorineural hearing loss. Hear Res 1989;42:47-72.

20) Wong AC, Ryan AF. Mechanisms of sensorineural cell damage, death and survival in the cochlea. Front Aging Neurosci 2015;7:58.

21) Takumida M, Ishibashi T, Hamamoto T, Hirakawa K, Anniko M.
Age-dependent changes in the expression of klotho protein, TRPV5 and TRPV6 in mouse inner ear. Acta Otolaryngol 2009;129:134050.

22) Pauler M, Schuknecht HF, Thornton AR. Correlative studies of cochlear neuronal loss with speech discrimination and pure-tone thresholds. Arch Otorhinolaryngol 1986;243:200-6.

23) Noguchi Y, Takahashi M, Ito T, Fujikawa T, Kawashima Y, Kitamura K. Delayed restoration of maximum speech discrimination scores in patients with idiopathic sudden sensorineural hearing loss. Auris Nasus Larynx 2016;43:495-500.

24) Fetterman BL, Saunders JE, Luxford WM. Prognosis and treatment of sudden sensorineural hearing loss. Am J Otol 1996;17:529-36.

25) Li P, Zeng XL, Ye J, Yang QT, Zhang GH, Li Y. Intratympanic methylprednisolone improves hearing function in refractory sudden sensorineural hearing loss: a control study. Audiol Neurootol 2011;16:198-202.

26) Lee JB, Choi SJ, Park K, Park HY, Choo OS, Choung YH. The efficiency of intratympanic dexamethasone injection as a sequential treatment after initial systemic steroid therapy for sudden sensorineural hearing loss. Eur Arch Otorhinolaryngol 2011;268:833-9.

27) Rauch SD, Halpin CF, Antonelli PJ, Babu S, Carey JP, Gantz BJ, et al. Oral vs intratympanic corticosteroid therapy for idiopathic sudden sensorineural hearing loss: a randomized trial. JAMA 2011;305: 2071-9.

28) Chou YF, Chen PR, Kuo IJ, Yu SH, Wen YH, Wu HP. Comparison of intermittent intratympanic steroid injection and near-continual transtympanic steroid perfusion as salvage treatments for sudden sensorineural hearing loss. Laryngoscope 2013;123:2264-9.

29) Suzuki H, Koizumi H, Ohkubo J, Hohchi N, Ikezaki S, Kitamura T. Hearing outcome does not depend on the interval of intratympanic steroid administration in idiopathic sudden sensorineural hearing loss. Eur Arch Otorhinolaryngol 2016;273:3101-7.

30) Ohyama K, Salt AN, Thalmann R. Volume flow rate of perilymph in the guinea-pig cochlea. Hear Res 1988;35:119-29.

31) Salt AN, Thalmann R, Marcus DC, Bohne BA. Direct measurement of longitudinal endolymph flow rate in the guinea pig cochlea. Hear Res 1986;23:141-51.

32) Salt AN, Hartsock JJ, Gill RM, Piu F, Plontke SK. Perilymph pharmacokinetics of markers and dexamethasone applied and sampled at the lateral semi-circular canal. J Assoc Res Otolaryngol 2012;13: 771-83. 